\title{
ENGEVISTA
}

Página da revista: http://www.uff.br/engevista/seer/

\section{Influência da incorporação de chamote nas propriedades físico-mecânicas de materiais cerâmicos estruturais}

\author{
Artidônio Dantas Prado ${ }^{1}$ \\ Ricardo Neves Bedoya ${ }^{2}$ \\ José Manuel Rivas Mercury ${ }^{3}$
}

Resumo: Neste artigo é estudada a influência da incorporação de tijolos descartados em pó (chamote) em concentrações variáveis $(0,10,20,30,40$ e 50\% em peso) a uma massa industrial constituída por misturas (1:1) de duas argilas cauliniticas. As matérias primas (argilas e chamote) foram caracterizadas, física, química e mineralogicamente, por Análise térmica (TG-DTA), Distribuição de tamanho de partículas (DTP) por difração de laser, Espectroscopia de fluorescência de raios X (FRX), Difração de Raios X (DRX) e Microscopia Eletrônica de Varredura (MEV). Corpos de prova contendo misturas de argila e chamote de dimensões $70 \times 30 \times 5 \mathrm{~mm}^{3}$ foram prensados uniaxialmente a $25 \mathrm{MPa}$ e secos a $110^{\circ} \mathrm{C}$. Os corpos de prova obtidos foram tratados termicamente em forno convencional e atmosfera normal nas temperaturas de $850,950,1050$ e $1150^{\circ} \mathrm{C}$, a uma taxa de aquecimento de $5^{\circ} \mathrm{C} / \mathrm{min}$ e patamar de 2 horas. As propriedades físico-mecânicas avaliadas foram: absorção de água (AA), retração linear de queima (RLq) e tensão de ruptura à flexão (TRF). Os resultados obtidos mostraram que os materiais tratados entre $850-950{ }^{\circ} \mathrm{C}$ apresentam valores de TRF que não ultrapassam $5 \mathrm{MPa}$, o que limita o uso destas massas para fabricação de tijolos furados (5,5 MPa) e telhas (6,5 MPa). Acima dos $950^{\circ} \mathrm{C}$ ocorre um incremento da TRF (> 5,5 MPa) obtendo-se materiais com boa resistência mecânica, AA moderada, com boas propriedades dimensionais (retração linear baixa) podendo ser classificados como revestimentos do tipo BIII e BIIb (Porosos e semi-porosos) de acordo com a norma da ABNT 13818.

Palavras-chave: Resíduos sólidos, Cerâmica vermelha, Adição de chamote.

\footnotetext{
${ }^{1}$ IFMA - Instituto Federal do Maranhão

2 UFERSA - Universidade Federal Rural do Semi-Árido

${ }^{3}$ IFMA - Instituto Federal do Maranhão

ENGEVISTA, V. 18, n. 1, p. 158-173, Julho 2016.
} 
ISSN: $1415-7314$

ISSN online: 2317-6717

Abstract : In this article was studied the influence of chamotte powder additions (0, 10, 20, 30, 40 and $50 \%$ by weight) to an industrial mass consisting of mixtures (1:1) of two kaolinitic clays. The chamotte was obtained from discarded bricks of the same industry. The raw materials (clays and chamotte) were characterized physical, chemical and minerlogically using thermal analysis (TG-DTA), particle size distribution (PSD) by laser diffraction, fluorescence X-ray spectroscopy (XRF), X-Ray Diffraction (XRD) and Scanning Electron Microscopy (SEM). Specimens containing mixtures of clay and grog dimensions of 70 x 30 x $5 \mathrm{~mm}^{3}$ were uniaxially pressed at $25 \mathrm{MPa}$ and dried at $110^{\circ} \mathrm{C}$. The obtained samples were heat-treated in a conventional furnace and normal atmosphere at temperatures of $850,950,1050$ and $1150{ }^{\circ} \mathrm{C}$ at a heating rate of $5{ }^{\circ} \mathrm{C} / \mathrm{min}$ and dwell time of 2 hour. The evaluated physical and mechanical properties were: water absorption (AA), linear fired shrinkage (RLq) and tensile strength (TRF). The results showed that the treated material present between $850-950^{\circ} \mathrm{C}$ values that do not exceed $5 \mathrm{MPa}$, which limits the use of these weights for the manufacture of hollow bricks (5.5 MPa) and shingles (6.5 MPa). Above $950^{\circ} \mathrm{C}$ there is an increase in $\mathrm{TRF}(>5.5 \mathrm{MPa})$ to yield materials with good mechanical strength, moderate AA with good dimensional properties (low linear shrinkage) may be classified as type coatings BIII and BIIb (Porous and semi-porous) according to the Brazilian Industrial Standard ABNT 13817.

Keywords: Solid wastes, Heavy clay; Chamotte additions. 


\section{Introdução}

A indústria de Cerâmica Vermelha no Brasil, segundo os dados da Associação Brasileira de Cerâmica, tem um faturamento anual de 18 bilhões de reais, uma produção distribuída por 7431 empresas gerando 293 mil empregos diretos e consumindo $10.3 \times 10^{6}$ ton/mês de argila, o que, sem dúvida, permite que seja considerada um setor de grande importância econômica e social (Soares do Prado e Bressiani, 2012). Porém, em várias regiões do país, ainda existem empresas de pequeno e médio porte (familiares), que utilizam processos produtivos antigos e ineficientes, que levam à produção de materiais cerâmicos estruturais de baixa qualidade e de pouca competitividade.

No Estado do Maranhão, mais especificamente, no município de Rosário está localizado um dos maiores polos de fabricação de cerâmica vermelha. Estas indústrias de pequeno, médio e grande porte estão localizadas às margens do rio Itapecuru sendo de grande importância socioeconômica para a região. Estima-se que existam nesta localidade mais de 20 empresas produtoras de blocos e telhas e artesanato. Os principais problemas na produção de materiais cerâmicos estruturais no Estado apontam à: 1) falta de conhecimento das matérias-primas quanto à composição química e mineralógica, propriedades tecnológicas (retração linear, porosidade aparente, absorção de água, resistência mecânica, etc.); 2) desconhecimento de parâmetros de processamento (pressão de prensagem, teor de umidade, formulação de massa, etc.); 3) falta de controle na secagem, descontrole no processo de queima e sinterização. Como consequência dessas falhas e a inadequação do processo de fabricação, uma grande quantidade de lenha de mata nativa é utilizada como combustível, sem a preocupação com o desmatamento indiscriminado e o replantio, o que contribui para a agressão ao meio ambiente. Todos estes problemas se refletem na qualidade do produto final o qual não atende aos requisitos mínimos exigidos pelas normas técnicas brasileiras (Correia et al., 2011), o que gera um grande volume de resíduos de tijolos queimados descartados. Estes materiais descartados podem ser reutilizados como materiais não-plásticos ou chamote em novas formulações de forma a diminuir o consumo de matérias primas e a agressão ao meio ambiente. Na literatura vários trabalhos têm sido realizados no sentido de estudar o efeito de adições de chamote na microestrutura e propriedades físico mecânicas de materiais como tijolos, telhas e revestimentos (Demira e Orhan, 2003; Vieira e Monteiro, 2006; 2007; Rajamannan et al.; 2013) mostrando que a retração linear de queima, a absorção de água e a tensão de ruptura a flexão não são afetadas de maneira significativa pelo uso deste resíduo o que indica viabilidade do uso deste material na produção de telhas e tijolos, porém torna-se necessário a otimização do tamanho de partícula, da composição e a temperatura de queima, de forma a se obter materiais com porosidade controlada. Neste trabalho foi estudada a influência da incorporação de chamote em concentrações variáveis $(0,10,20,30,40$ e $50 \%$ em peso) a uma massa cerâmica de uma indústria 
do Estado do Maranhão visando à minimização de resíduos e a diminuição do consumo de matérias primas.

\section{Materiais e Métodos}

\subsection{Matérias}

Amostras de duas argilas (50 kg) foram coletadas no barreiro de uma indústria de cerâmica vermelha localizada no município de Rosário (MA). Estas argilas foram denominadas aqui de argila A e B.

A argila A apresentou-se relativamente plástica (ao tacto), já a argila B é menos plástica. Ambas são utilizadas em fabrica na proporção de 1:1 para a obtenção de Tijolos e Telhas. As argilas coletadas em forma de torrões foram quarteadas e uma alíquota $(7 \mathrm{~kg})$ foi seca ao ar durante 48 h. Após, ambas as argilas foram desagregadas por trituração para obter-se grânulos abaixo de 3 $\mathrm{mm}$ que foram submetidos à moagem em moinho de disco, para se obter um material com tamanho inferior a $250 \mu \mathrm{m}$ (60 mesh). Este material foi quarteado novamente para se retirar uma alíquota de $5 \mathrm{~kg}$, usada na preparação das massas e corpos de prova para realização dos ensaios físico-químicos e de caracterização e tecnológica.

Rejeito de tijolos queimados $(40 \mathrm{~kg}$ ) descartados, produzidos com as mesmas argilas citadas no item anterior, foi denominado por R1. Este material foi coletado em fabrica, quarteado (7 $\mathrm{kg})$ e seco em estufa a $110{ }^{\circ} \mathrm{C}$ por 24 horas, logo após, foi moído em moinho de disco até se obter um material passante pela peneira 60 (inferior a $250 \mu \mathrm{m}$ ). Deste material foram retirados $5 \mathrm{~kg}$ para preparação dos corpos de prova $\left(\mathrm{CP}^{\prime} \mathrm{s}\right)$ e preparação das massas para realização dos ensaios de caracterização físico-química e tecnológica.

\subsection{Formulação de Massas}

Para formulação das massas cerâmicas estudadas neste trabalho foi levado em conta a seguinte tabela de composições: 
Tabela 1. Quadro de formulação de massas com chamote de tijolo.

\begin{tabular}{ccccccc}
\hline \multirow{2}{*}{ Matéria primas } & \multicolumn{6}{c}{ Composição (\% em peso) } \\
\cline { 2 - 7 } & C1 & C2 & C3 & C4 & C5 & C6 \\
\hline Argila A & 50 & 45 & 40 & 35 & 30 & 25 \\
Argila B & 50 & 45 & 40 & 35 & 30 & 25 \\
R1 & 0 & 10 & 20 & 30 & 40 & 50 \\
\hline
\end{tabular}

\subsection{Métodos}

\subsubsection{Análise Química}

A análise química para determinação do conteúdo de silício ( $\mathrm{Si}$ ), alumínio (Al), ferro ( $\mathrm{Fe}$ ), cálcio $(\mathrm{Ca})$, magnésio $(\mathrm{Mg})$, potássio $(\mathrm{K})$, sódio $(\mathrm{Na})$, fósforo $(\mathrm{P})$, manganês $(\mathrm{Mn})$ e titânio $(\mathrm{Ti})$ presentes nas diferentes materiais primas foi realizada por Espectrometria de Florescência de Raios X (FRX) num espectrômetro modelo PW-2400-00, marca PHILIPS. Para a determinação quantitativa foram preparadas pastilhas, por fusão, com $\mathrm{Li}_{2} \mathrm{~B}_{4} \mathrm{O}_{7}(7,23005 \mathrm{~g})$ e $0,8000 \mathrm{~g}$ de amostra. Os resultados foram expressos na forma dos óxidos constituintes.

\subsubsection{Difração de Raios $X$}

A identificação das fases minerais presentes nas matérias-primas, foi utilizado um Difratômetro de Raios X modelo XRD- 6000 Shimadzu. A coleta dos espectros foi realizada no ângulo de varredura de $5-70^{\circ}(2 \Theta)$ usando como radiação $\mathrm{Cu}-\mathrm{K}_{1} \alpha(\lambda=1,54056 \AA$ ), no modo de varredura continua, voltagem $30 \mathrm{kV}$ e corrente $30 \mathrm{~mA}$ e velocidade de varredura de $2 \% \mathrm{~min}$. A identificação das fases de cada matéria-prima analisada foi dada por comparação entre os picos gerados no difratograma com cartas padrões no software JCPDF cadastradas no ICDD (Internacional Centre for Difracction Data). 


\subsubsection{Análise Térmica}

O comportamento térmico das matérias primas $(100 \mathrm{mg})$ foi estudado por análise térmico diferencial (DTA) e termogravimétrica (TG) no intervalo $20-1200{ }^{\circ} \mathrm{C}$ usando-se hélio como gás de araste a uma taxa de aquecimento de $10^{\circ} \mathrm{C} / \mathrm{min}$ da temperatura ambiente até $1200^{\circ} \mathrm{C}$.

\subsubsection{Distribuição Granulométrica}

Para a determinação da distribuição do tamanho de partícula e/ou aglomerado das matérias primas foi utilizado um granulômetro à Laser modelo 920L, Cilas, no intervalo de 0,01 a $1000 \mu \mathrm{m}$. Uma suspensão contendo $2 \mathrm{~g}$ de amostra e $2 \mathrm{~mL}$ de detergente neutro em $10 \mathrm{~mL}$ de água destilada foi preparada e dispersa durante $60 \mathrm{~s}$ em ultrassom. $\mathrm{O}$ resultado das medidas foi analisado com o uso do programa The Particle Expert.

\subsubsection{Propriedades Tecnológicas}

Para determinação das propriedades cerâmicas das matérias primas e composições Tabelas 3.1 foram prensados uniaxialmente a $25 \mathrm{MPa}$ corpos de prova (CP's) de dimensões de 70 x 30 x 5 $\mathrm{mm}^{3}$ com $8 \%$ de umidade. Estes CP's foram secos em estufa a $110{ }^{\circ} \mathrm{C}$ por 24 horas e sinterizados em atmosfera normal nas temperaturas de $850,950,1050$ e $1150^{\circ} \mathrm{C}$, usando uma taxa de aquecimento de $5{ }^{\circ} \mathrm{C} /$ min e patamar de 2 horas. Após sinterização foram determinadas: Absorção de Água (AA) e Retração linear de queima $\left(\mathbf{R}_{\mathrm{Lq}}\right)$, de acordo de acordo com a norma NBR 6220/2011 da ABNT. Para a determinação da Tensão de ruptura a flexão em três pontos das amostras sinterizadas foi utilizada uma máquina de ensaios mecânico universal Tiratest (2024) com distância entre os apoios foi de $40 \mathrm{~mm}$. A velocidade de ensaio foi de $1 \mathrm{~mm} / \mathrm{min}$. Conforme norma ASTM - D790.

\subsubsection{Microscopia Eletrônica de Varredura}

A análise por microscopia eletrônica de varredura da microestrutura dos materiais aqui estudados foi realizada na superfície de fratura de um corpo cerâmico submetido à flexão num Microscópio Eletrônico de Varredura modelo XL 30 - ESEM marca Phillips. 


\section{Resultados e discussão}

\subsection{Análise química das materiais primas}

Os resultados das análises químicas realizadas nas matérias primas apresenta-se na Tabela 3.1.

$\mathrm{Na}$ tabela se observa que as argilas $\mathrm{A}, \mathrm{B}$ apresentam teores de $\mathrm{SiO}_{2}$ semelhantes superiores a $66 \%$. O teor de $\mathrm{Al}_{2} \mathrm{O}_{3}$ presente nestes materiais situa-se entre 15 e $18 \%$. Estes valores permitem calcular relações de $\mathrm{SiO}_{2} / \mathrm{Al}_{2} \mathrm{O}_{3}$ de 3,84, 4,16, valores superiores a 1,17 indicando a presença de minerais do tipo caulinita e quartzo livre em elevadas quantidades (Souza Santos, 1989).

\begin{tabular}{cccc}
\hline \multicolumn{4}{c}{ Tabela 3.1. Análise química das matérias primas } \\
\hline \multicolumn{4}{c}{ \% em peso } \\
\hline Determinação & Argila A & Argila B & $\mathrm{R} 1$ \\
\hline $\mathrm{SiO}_{2}$ & 66,43 & 66,18 & 68,97 \\
$\mathrm{Al}_{2} \mathrm{O}_{3}$ & 17,30 & 15,89 & 17,31 \\
$\mathrm{Fe}_{2} \mathrm{O}_{3}$ & 6,67 & 5,89 & 6,65 \\
$\mathrm{CaO}$ & 0,11 & 0,18 & 0,12 \\
$\mathrm{MgO}$ & 0,54 & 0,99 & 0,70 \\
$\mathrm{Na}_{2} \mathrm{O}$ & 0,21 & 0,97 & 0,54 \\
$\mathrm{~K}_{2} \mathrm{O}$ & 1,14 & 3,04 & 2,11 \\
$\mathrm{MnO}_{2}$ & 0,02 & 0,04 & 0,03 \\
$\mathrm{TiO}_{2}$ & 1,38 & 1,07 & 1,25 \\
$\mathrm{P}_{2} \mathrm{O}_{5}$ & 0,07 & 0,10 & 0,07 \\
$\mathrm{PF}$ & 6,20 & 5,65 & 2,25 \\
\hline Total $(\%)$ & 100,00 & 100,00 & 100,00 \\
\hline
\end{tabular}

Observa-se também, teores de $\mathrm{Fe}_{2} \mathrm{O}_{3}$ superiores a 5\% em peso para ambas as argilas o que sugere a presença de minerais de ferro provavelmente hematita ou goethita e que as mesmas deverão apresentar após queima coloração vermelha. A concentração dos óxidos alcalinos terrosos $(\mathrm{MgO}+\mathrm{CaO})$ e dos alcalinos $\left(\mathrm{Na}_{2} \mathrm{O}+\mathrm{K}_{2} \mathrm{O}\right)$ na argila $\mathrm{A}$ não ultrapassa $1 \%$ em peso, o que permite afirmar que esta argila sofreu um intenso processo de intemperismo e lixiviação, não apresentando feldspatos na sua composição. Já a argila $\mathrm{B}$, apresenta concentração de alcalinos terrosos inferior a $2 \%$ em peso e alcalinos na ordem de $4 \%$ em peso, indicando a presença de feldspatos e/ou micas. A perda ao fogo em ambas materiais primas e inferior a $7 \%$ em peso, perda geralmente associada a constituintes voláteis (água), queima de matéria orgânica e decomposição de carbonatos (Souza Santos, 1989) e caulinita, valor inferior à perda de massa teórica da caulinita $(13,97 \%)$, o que confirma parcialmente a presença de elevados teores quartzo. O resíduo R1 apresenta uma composição química semelhante às argilas como deveria se esperar, uma vez que o mesmo é o resultado da mistura das argilas A e B. 


\subsection{Mineralogia das materiais primas}

A Figura 3.1 mostra o resultado da análise por DRX das matérias primas estudadas.

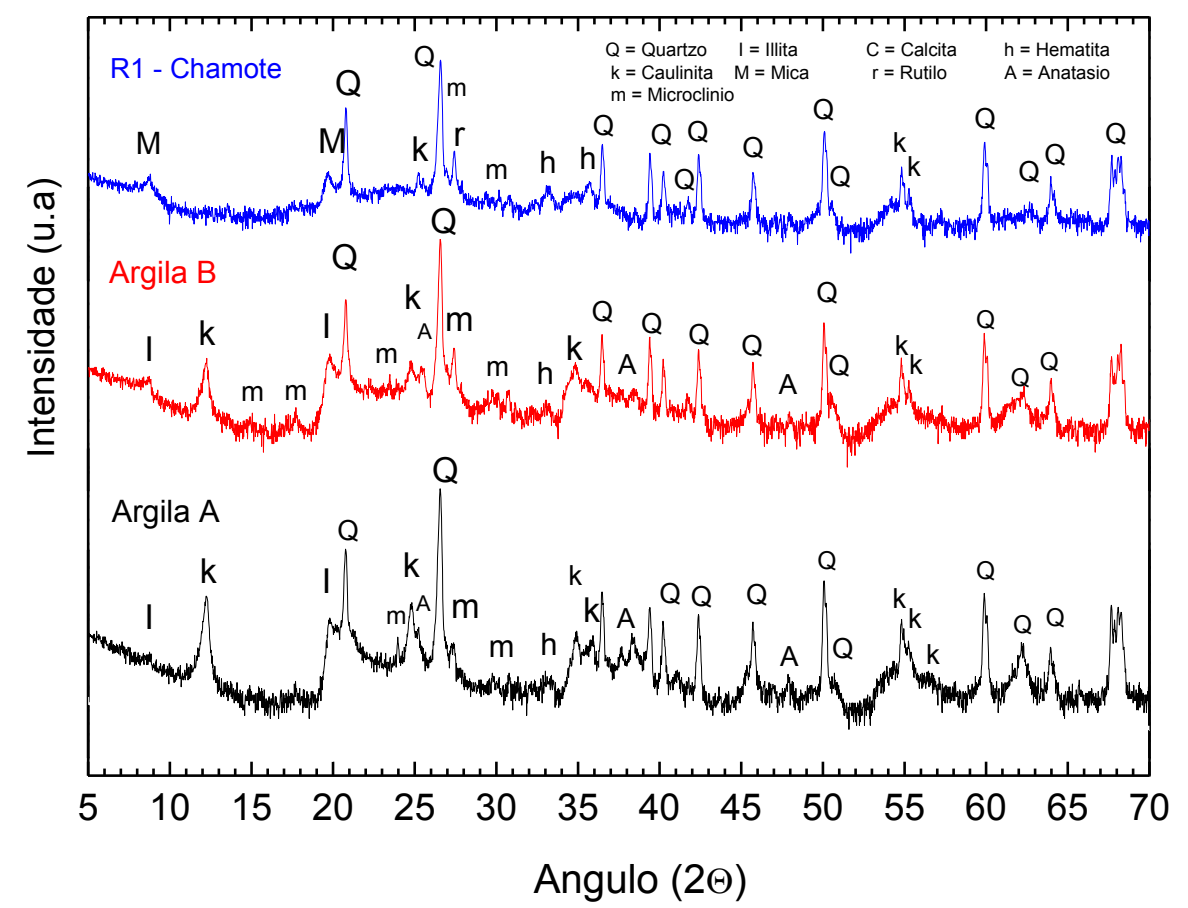

Figura 3.1. - Difração de raios $X$ das materiais primas.

Pode-se observar que ambas as Argilas (A e B) apresentam uma composição mineralógica semelhante constituídas pelas fases minerais Quartzo $\left(2 \Theta=23,45^{\circ}\right.$ - PDF-00-005-0490), Caulinita $\left(2 \Theta=12,27^{\circ}\right.$ - PDF-00-014-0164), Microclínio $\left(2 \Theta=27,45^{\circ}\right.$ - PDF- 00-010-0479), Hematita $\left(2 \Theta=33,20^{\circ}\right.$ - PDF- 00-033-0664), Anatásio $\left(2 \Theta=25,23^{\circ}\right.$ - PDF- 00-004-047) e Ilita $(2 \Theta=26,67$ e 8,82 ; PDF- 00-026-0911). A chamota constituída por resíduos de refugos de tijolos descartados queimados (resíduo R1) apresenta uma mineralogia semelhante às argilas anteriores com ausência de Ilita e Anatásio que por ação da temperatura deram lugar a Mica e Rutilo (Mercury et al.; 2012). Estes resultados estão de acordo com os resultados da análise química que mostra elevados teores de alcalinos $\left(\mathrm{Na}_{2} \mathrm{O}+\mathrm{K}_{2} \mathrm{O}=5 \%\right)$ o que confirma a presença de Ilita, Mica e compostos de tipo feldespatoide como Microclínio na composição.

\subsection{Comportamento térmico das matérias primas.}

Considerando que as argilas A e B apresentam a mesma mineralogia o que indica tratar-se da mesma matéria prima, portanto será aqui mostrado somente o termograma da Argila (Figura 3.2) A. 


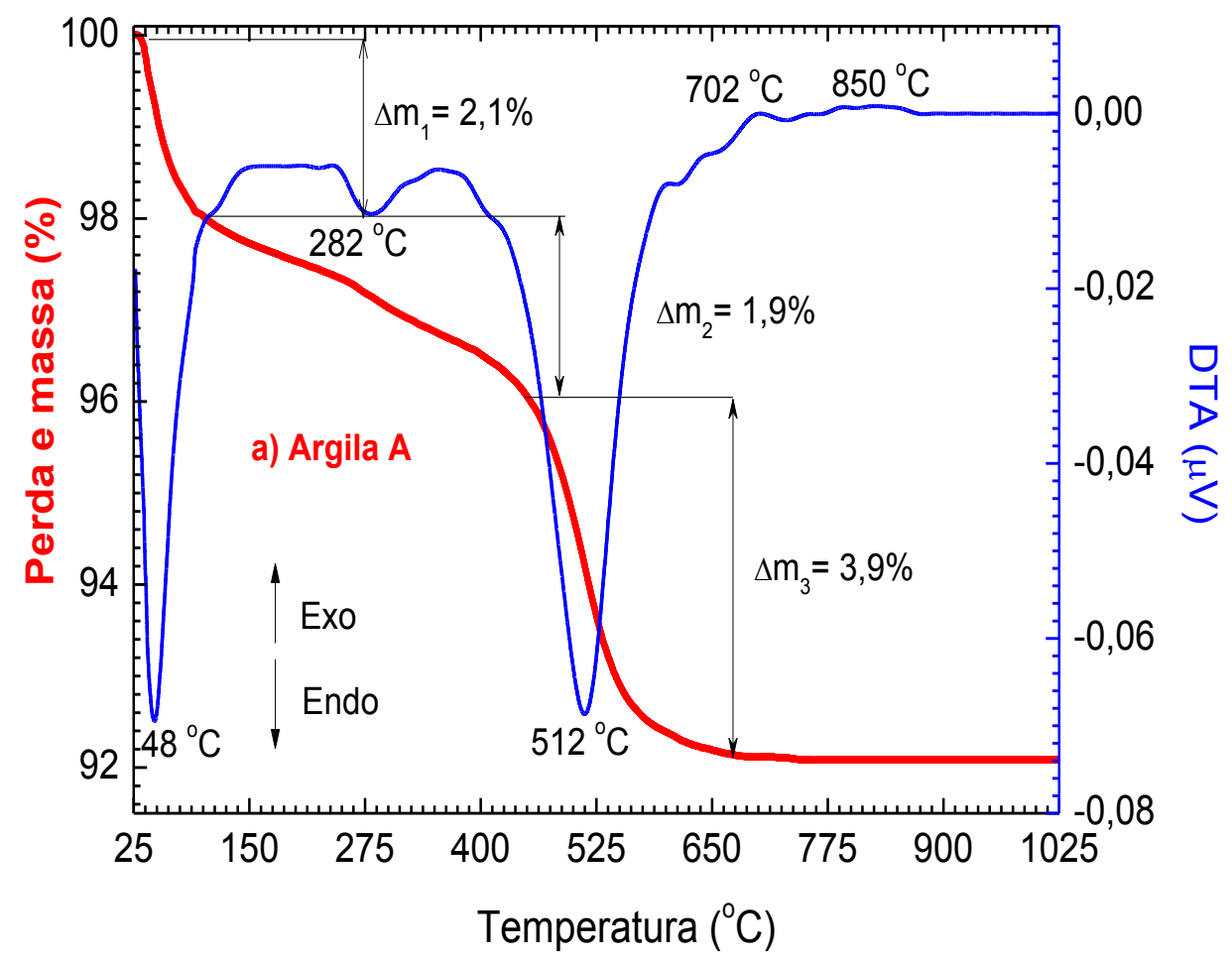

Figura 3.2. Termogramas da Argila A; obtido a $10{ }^{\circ} \mathrm{C} / \mathrm{min}$.

Pode-se observar na curva TG que a Argila A apresenta uma perda de massa de $8 \%$ o que esta de acordo com o valor da perda ao fogo observada na análise química. Esta perda de massa ocorre em três estágios com transformações endotérmicas que se observam claramente na curva DTA: A primeira entre $45-135{ }^{\circ} \mathrm{C}$ que corresponde a $2,1 \%$ com máximo na curva DTA a $48{ }^{\circ} \mathrm{C}$ devido à perda de água livre e início da liberação da água adsorvida nas partículas da argila. A segunda perda de $1,9 \%$ ocorre entre $135-450{ }^{\circ} \mathrm{C}$ um pico endotérmico a $282{ }^{\circ} \mathrm{C}$, que está associada à volatilização ou oxidação de restos de matéria orgânica e à desidroxilação de pequenas quantidades de ilita presente no material. A última perda de 3,9\% corresponde a desidroxilação da caulinita cujo máximo se observa na curva DTA a $512{ }^{\circ} \mathrm{C}$, indicando a destruição da estrutura cristalina da caulinita (amorfização) com formação de metacaulinita de acordo com a seguinte reação:

$$
3 \mathrm{Al}_{2} \mathrm{Si}_{2} \mathrm{O}_{5}(\mathrm{OH})_{4} \rightarrow \mathrm{Al}_{6} \mathrm{Si}_{2} \mathrm{O}_{11}+6 \mathrm{H}_{2} \mathrm{O}
$$

Finalmente na Figura 3.2 se observam dois efeitos exotérmicos de pouca intensidade: um a $702{ }^{\circ} \mathrm{C}$ cuja banda se atribui à transformação Anatásio $\rightarrow$ Rutilo (Hanaor \& Sorrel, 2011) e outra banda a $850^{\circ} \mathrm{C}$ que está relacionada à nucleação da mulita (Sánchez \& Carda, 2002). 


\subsection{Tamanho de partícula e morfologia do chamote.}

A Tabela 3.2 mostram o resultado da distribuição dos tamanhos de partículas das materiais primas estudadas.

Tabela 3.2. Distribuição granulométrica das matérias primas.

\begin{tabular}{cccc}
\hline Matéria prima & $\mathrm{D}_{10}(\mu \mathrm{m})$ & $\mathrm{D}_{50}(\mu \mathrm{m})$ & $\mathrm{D}_{90}(\mu \mathrm{m})$ \\
\hline Argila A & 0,63 & 2,99 & 11,59 \\
Argila B & 0,74 & 4,27 & 15,93 \\
R1 & 0,63 & 4,70 & 37,87 \\
\hline
\end{tabular}

Na Tabela se observa que as matérias primas apresentam $\mathrm{D}_{50}$ semelhantes variando entre 3$7 \mu \mathrm{m}$. Também se observa claramente que o resíduo (R1) apresenta um valor de $\mathrm{D}_{90}$ (decil correspondente a $90 \%$ das partículas com tamanho menor que o valor dado) superior a $35 \mu \mathrm{m}$, valor este duas vezes maior que os apresentados pelas argilas A e B. Estes valores são apropriados para o processamento de materiais tradicionais.

A morfologia do resíduo R1 utilizado neste trabalho foi obtida por MEV é mostrada na Figura 3.3 (a-b). Pode-se observar nesta (Figura 3.3-a) que o resíduo R1 é constituído por partículas irregulares de tamanho inferior a $20 \mu \mathrm{m}$. A maiores aumentos $5000 \mathrm{X}$ se observa na Figura 3.3-b uma grande quantidade de partículas de tamanho inferior a $5 \mu \mathrm{m}$ de aspecto arredondado irregular, provavelmente resultantes do processo de moagem a que foi submetida esta matéria prima, também se observam partículas com a mesma morfologia porém de tamanhos superiores $5 \mu \mathrm{m}$. 

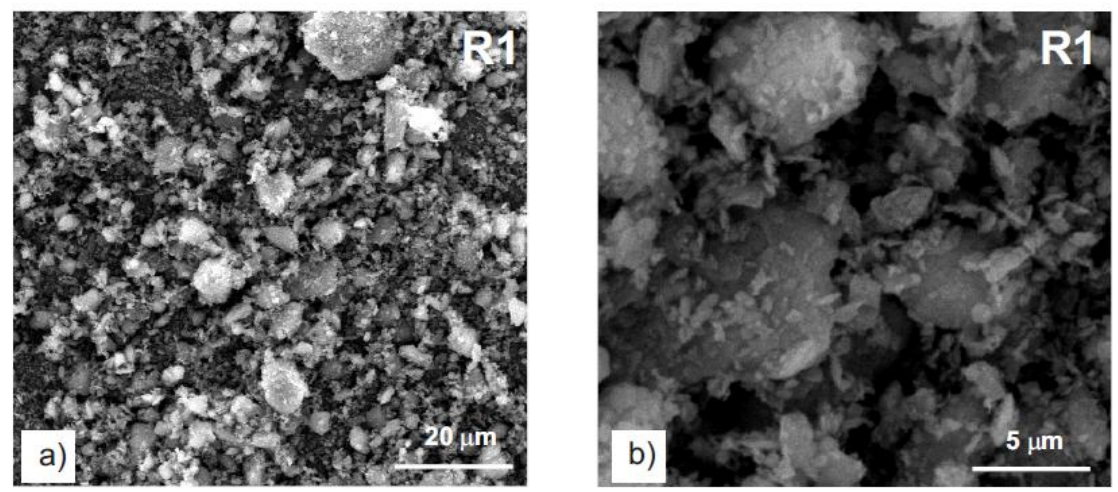

Figura 3.3. Micrografia obtida por MEV das partículas do Chamote (R1): a) - Aumento de 1000X SE; b) - Aumento de 5000X SE.

\subsection{Características cerâmicas das composições estudadas após a queima.}

A Figura 3.4-(a-b) mostra a curvas de gresificação dos materiais contendo mistura de argila A e $\mathrm{B}$ na proporção de 1:1 à qual foi adicionada $\mathrm{R} 1$ até o máximo de $50 \%$ em peso.

A relação 1:1 da mistura das argilas A e B foi mantida devido a ser esta proporção a utilizada pelo fabrica na obtenção dos blocos.

Na Figura 3.4-(a) se observa para as massas de composição C1, C2, e C3 (massas com teores de $\mathrm{R} 1$ de 0,10 e $20 \%$ em peso) que nas temperaturas de 850 e $950{ }^{\circ} \mathrm{C}$ os materiais apresentam um baixa $\mathrm{R}_{\mathrm{Lq}}$ não ultrapassando $2 \%$, a partir dos $950{ }^{\circ} \mathrm{C}$ observa-se um incremento da desta propriedade que atinge aos $1150{ }^{\circ} \mathrm{C}$ valores inferiores a $8 \%$. Já os valores de AA indicam que o material é poroso (13-17\%) entre as temperaturas de cocção de 850 e $950^{\circ} \mathrm{C}$, acima destas temperaturas observa-se uma acentuada diminuição da AA (5-9\%) indicando a sinterização do material.

Já as composições C4, C5, e C6, (massas com teores do R1 de 30, 40 e 50\% em peso) são mostradas na Figura 3.4-(b), onde se pode observar que estas massas apresentam um comportamento semelhante às anteriores, com baixa retração linear de queima às temperaturas características de queima de materiais cerâmicos estruturais $\left(850-950{ }^{\circ} \mathrm{C}\right)$ não ultrapassando $2 \%$. Com o incremento de temperatura dos $950{ }^{\circ} \mathrm{C}$ até os $1150{ }^{\circ} \mathrm{C}$, os valores de retração linear de queima se incrementam não ultrapassando os $8 \%$ para todas as composições. 

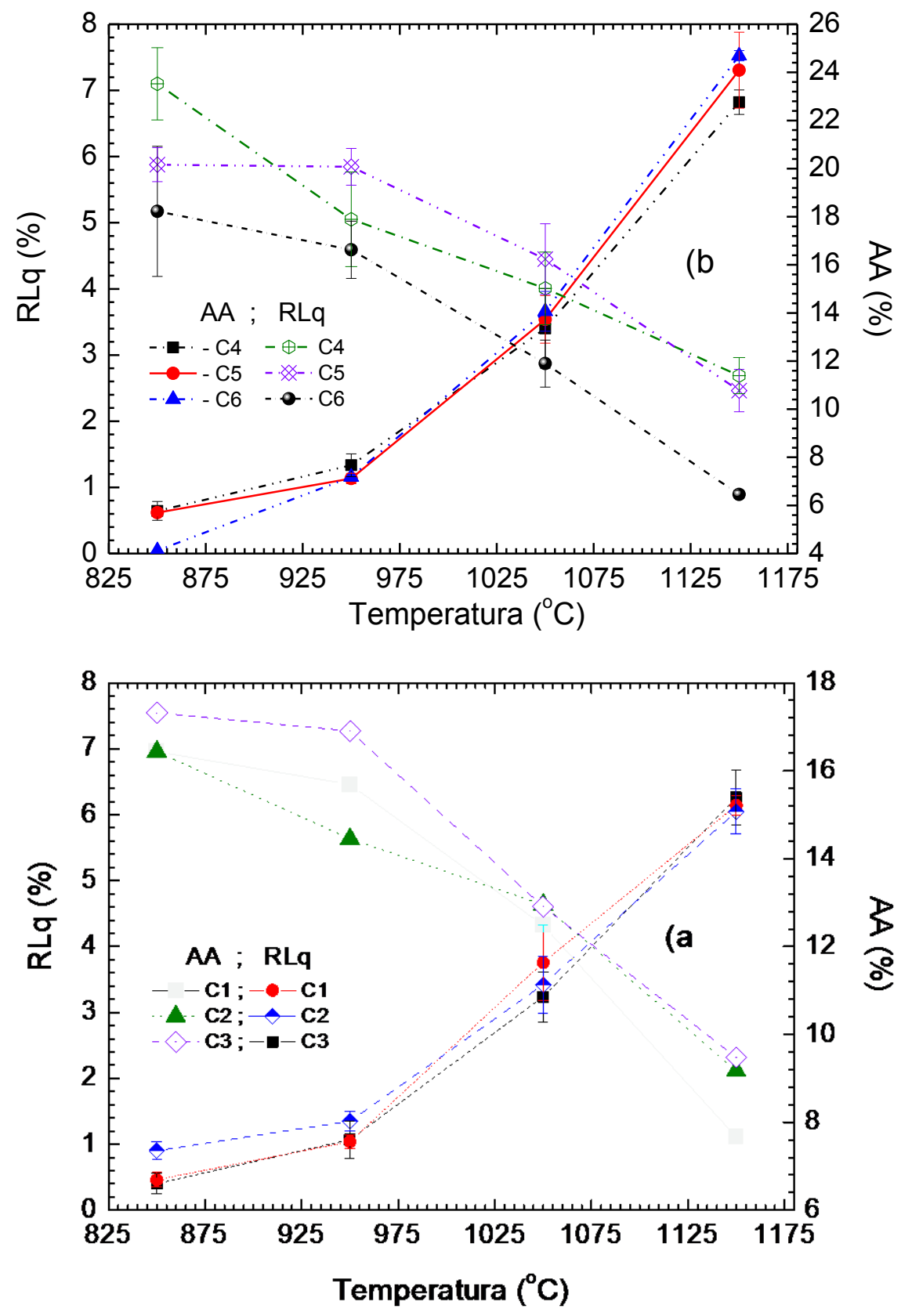

Figura 3.4. Curva de gresificação dos materiais contendo diferentes concentrações do resíduo R1. a) Variação de R1 entre 0 e $20 \%$ em peso. b) Variação de R1 entre 30 e 50 \% em peso.

Na Figura 3.5 pode-se observar que em todas as temperaturas de queima, o valor de tensão de ruptura à flexão diminui com o aumento da quantidade do resíduo R1 incorporado à massa. Todas as composições apresentam também uma resistência mecânica inferior à apresentada pelos materiais obtidos com a composição $\mathrm{C}$ 1. Este comportamento ocorre devido ao caráter inerte do 
resíduo (não plásticos), o qual dificulta as reações de sinterização o que também explica os baixos valores de retração linear (Vieira, 2006).

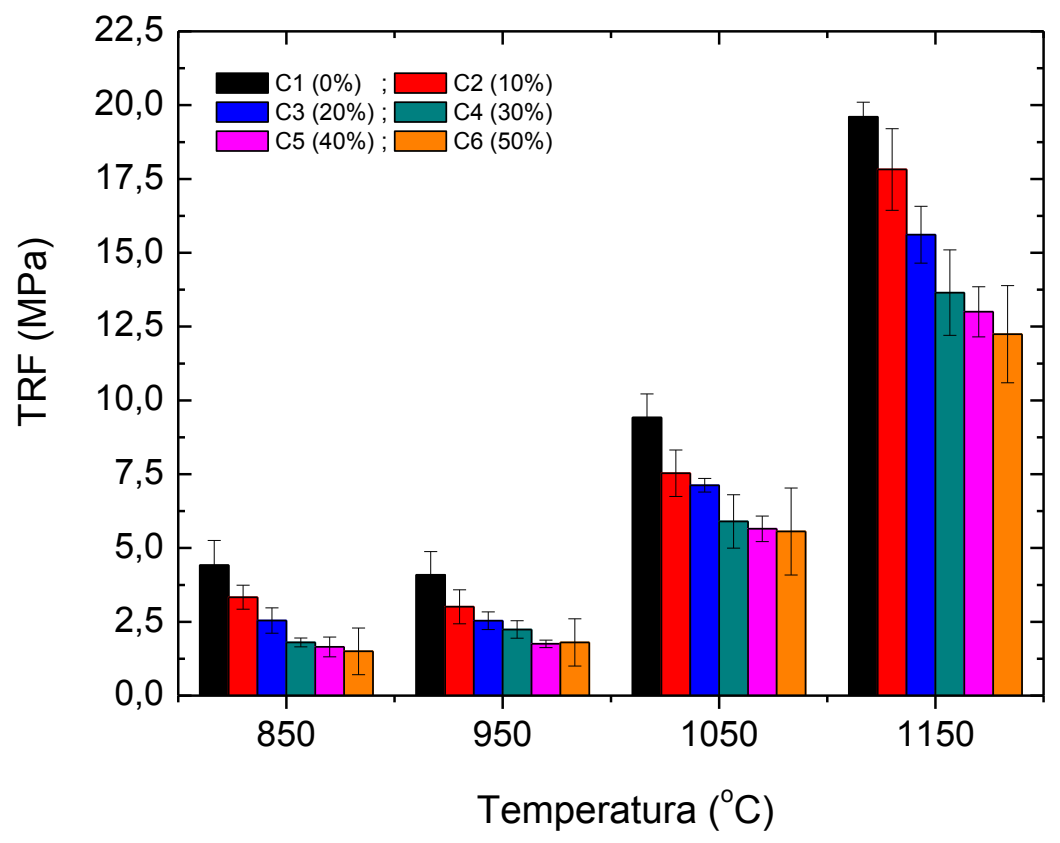

Figura 3.5. Tensão de Ruptura a Flexão em função do teor de R1 incorporado e da temperatura de queima.

Também se observa na mesma figura que os valores de TRF a $850{ }^{\circ} \mathrm{C}$ e $950{ }^{\circ} \mathrm{C}$ não ultrapassam os $5 \mathrm{MPa}$, o que limita o uso destas massas para fabricação de tijolos furados $(5,5$ $\mathrm{MPa})$ e telhas (6,5 MPa).

Acima dos $950^{\circ} \mathrm{C}$ ocorre um incremento da TRF nas massas contendo, superando o valor limite de 5,5 MPa indicando que as massas tratadas termicamente a estas temperaturas apresentam elevadas propriedades mecânicas, ideais para a produção de materiais cerâmicos estruturais. A melhoria das propriedades mecânicas observada após queima no intervalo de $1050-1150{ }^{\circ} \mathrm{C}$ está associada à formação de fase líquida responsável pela diminuição da porosidade e fechamento dos poros (Vieira, 2007). Os resultados obtidos estão de acordo com a norma NBR 13817 (NBR 13817; 1997) para classificação de revestimento cerâmico prensado. Estes resultados põem em evidencia que a adição de chamote de tijolo queimado (R1) entre 10-50\% em peso à massa constituída pela mistura das argilas A e B, permite obter materiais com boa resistência mecânica, AA moderada, com boas propriedades dimensionais (retração linear baixa) podendo ser classificados como revestimentos do tipo BIII e B IIb (Porosos e semi-porosos) de acordo com as normas da ABNT 13817 (ABNT 13817, 1997). 


\subsection{Cor após queima e microestrutura dos materiais sinterizados}

A Figura 3.6 apresenta as micrografias da superfície de fratura obtida por MEV dos materiais com $30 \%$ de chamote tratados a $950{ }^{\circ} \mathrm{C}$ e $1050{ }^{\circ} \mathrm{C}$.
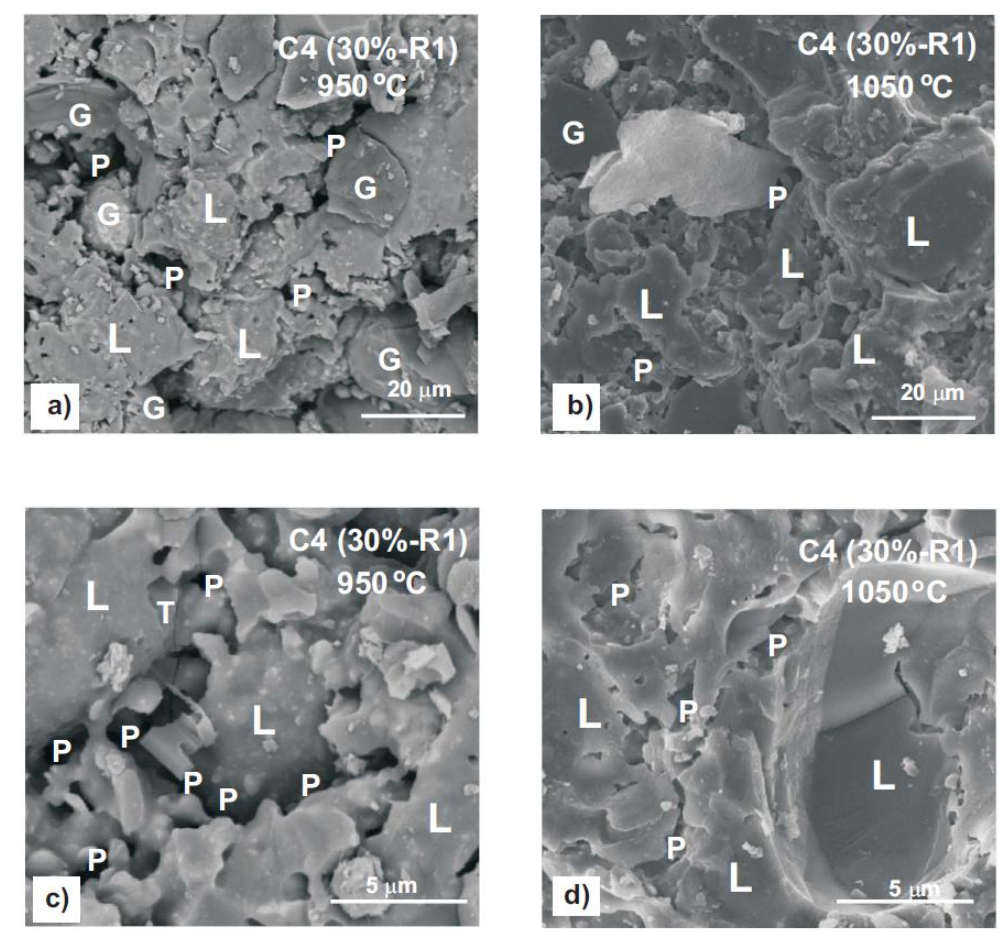

Figura 3.6. Micrografia da superfície de fratura obtida por MEV de materiais com incorporação de $30 \%$ de chamote: a e c) $950{ }^{\circ} \mathrm{C}$, b e d) $1050{ }^{\circ} \mathrm{C}$.

Observa-se nas micrografias que a $950{ }^{\circ} \mathrm{C}$ (Figura 3.4-a) o material apresenta uma superfície de fratura rugosa, devido provavelmente ao arranque de material durante a fratura. É possível observar também, uma grande quantidade de poros $(\mathrm{P})$ com grãos de tamanho superior a $20 \mu \mathrm{m}$ (provavelmente quartzo). A textura mais laminada da massa cerâmica (L) indica formação de liquido responsável pela coesão das partículas, apesar da elevada porosidade (aberta e interconectada) obtida. Maiores aumentos permitem observar na micrografia (Figura 5.11-c) uma fase liquida continua que rodeia partículas de menor tamanho e elevada porosidade, também se observa a presença de trincas. Com o aumento da temperatura para $1050{ }^{\circ} \mathrm{C}$ o processo de sinterização se intensifica e o material apresenta menos poros e abundante fase liquida, indicando que a amostra sofreu um processo de vitrificação o que explica os valores de TRF observados na (Figuras 3.5).

Na Figura 3.7 apresenta-se a sequencia de cores obtidas após queima a diferentes temperaturas dos corpos cerâmicos com a adição do resíduo R1. 


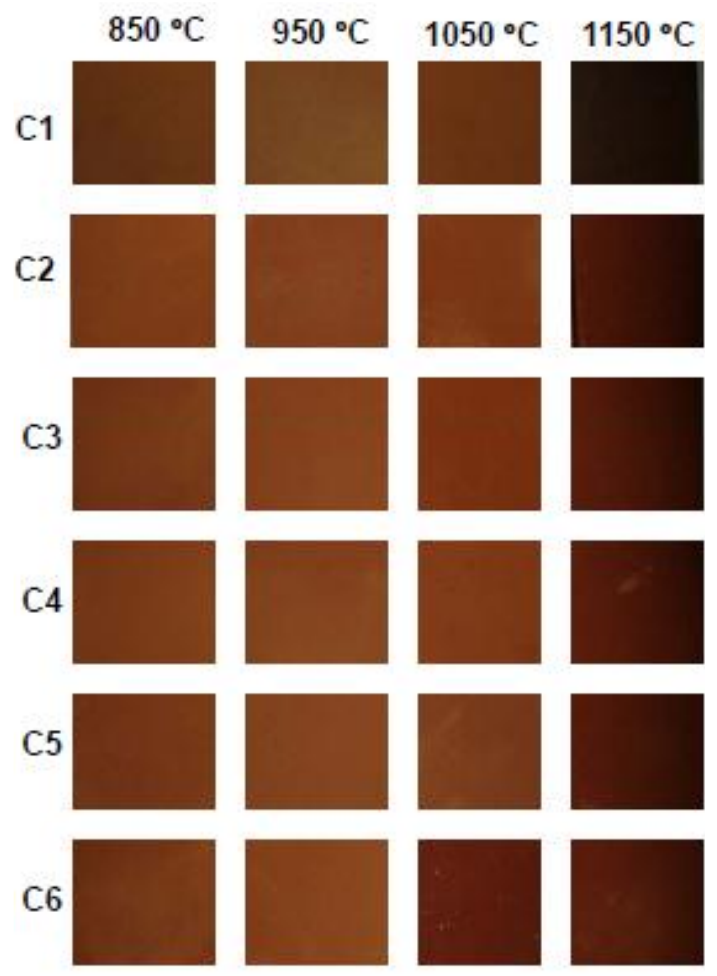

Figura 3.7. Cor de queima a diferentes temperaturas dos corpos cerâmicos contendo chamote R1 no intervalo de $0-50 \%$ em peso.

Nota-se na figura acima que a cor de queima variou nos tons marrom claro e marrom escuro. Nas temperaturas de 850 a $1050{ }^{\circ} \mathrm{C}$, para as composições C2 até C5 não houve variação significativa nas tonalidades dos materiais obtidos. Todos os materiais tratados termicamente a $1150{ }^{\circ} \mathrm{C}$ apresentaram coloração mais escura, isto se deve à presença de teores de $\mathrm{Fe}_{2} \mathrm{O}_{3}$ maiores que $3 \%$ que a esta temperatura começam a sofrer o processo de super queima, onde o ferro trivalente começa a reduzir gerando a cor marrom avermelhado escuro a preto (Roveri et al., 2007).

\section{Conclusões}

Os resultados deste estudo permitem concluir que não é viável incorporar o resíduo de tijolo em pó (chamote) à massa industrial para produção de materiais cerâmicos às temperaturas de sinterização iguais e inferiores a $950^{\circ} \mathrm{C}$, uma vez que estes apresentam elevada absorção de água e baixas tensões de ruptura à flexão sendo os materiais produzidos inadequados para a fabricação de tijolos e telhas.

Os materiais tratados as temperaturas acima de $950{ }^{\circ} \mathrm{C}$ apresentam valores de absorção de água e tensão de ruptura a flexão que superam os recomendados pela norma NBR 13817 o que permite classificar os materiais obtidos como revestimento semiporoso (BIIb) e poroso (BIII). 
Para a produção de materiais para revestimento semiporoso (BIIb) e poroso (BIII), é possível incorporar a massa industrial até $50 \%$ em peso de chamote o que representaria uma economia no consumo de materiais primas.

\section{Agradecimentos}

À Fundação de Amparo à Pesquisa do Estado do Maranhão - FAPEMA

\section{Referencias}

Associação Brasileira de Normas Técnicas (ABNT). NBR 13818. Placas cerâmicas para revestimento. Especificação e métodos de ensaios. Rio de Janeiro, 1997. 78p.

CORREIA, G. S. 2011. Caracterização de massas cerâmicas e avaliação da conformidade dos blocos de vedação fabricados no município de itapecuru mirim-MA. Dissertação de Mestrado. Instituto Federal do Maranhão.

DEMIR, I., ORHAN, M. 2003. Reuse of waste bricks in the production line. Building and Environment, V. 38, n. 12, pp. 1451-1455.

HANAOR, D. A. H., SORREL, C. C. 2011. Review of the of the anatase to rutile phase transformation. Journal of Materials Science. V.46, n. 4, pp 855-874.

MERCURY, J. M. R., CORREIA, G. S., VASCONCELOS, N. S. S. L., CABRAL, A. A. JR.; ANGÉLICA, R. S. 2012. Ceramic raw materials from the State of Maranhão, Brazil. Part 1: chemical and mineralogical characterization and technological properties of clays from São Luis, Rosário, Pinheiro and Mirinzal. São Luís. Rev. Esc. Minas. v. 65, n.4, pp. 513-521.

ROVERI, C. D., ZANARDO, A., MORENO, M. M. T. 2007. Variação da cor e propriedades cerâmicas com o aumento da temperatura de queima de uma argila proveniente da formação Corumbataí, região de Piracicaba, SP. Cerâmica, v. 53, n vvv, pp. 436-441.

SÁNCHEZ-MUÑOZ L. E CARDA J. B. Materias primas y aditivos cerámicos. Enciclopedia Cerámica. Tomo 2.2. cap. IX (2002). Ed: Faenza Editrice Ibérica S.L.

SOUZA SANTOS, P. 1992. Ciência e Tecnologia de Argilas. V. I. Edgard Blücher. São Paulo. SOARES DO PRADO, U., e BRESSIANI J. C. 2013. Panorama da Indústria Cerâmica Brasileira na Última Década. Cerâmica Industrial, V. 18, n. 1, pp. 7-11.

VIEIRA, C.M.F., MONTEIRO, S.N. 2007. Effect of grog addition on the properties and microstructure of a red ceramic body for brick production. Construction \& Building Materials, v. 21, n.8, pp. 1754-1759.

VIEIRA, C.M.F., MONTEIRO, S.N. 2006. Effect of the particle size of the grog on the properties and microstructure of bricks. Materials Science Forum, v. 530, pp. 438-443.

RAJAMANAN B., VIRUTHAGIRI G. e JAWAHAR K.S. Effect of grog addition on the Technological properties of ceramic Brick. International Journal of Latest Research in Science and Technology V. 2, n. 6, pp. 81-84. 2013 